\title{
Development of Smartphone Application Based on the Theory of Planned Behaviour to Enhance Self-Efficacy for Online Learning
}

\author{
https://doi.org/10.3991/ijim.v12i4.8715 \\ Chattavut Peechapol, Jaitip Na-Songkhla ${ }^{(凶)}$, Siridej Sujiva, Arthorn Luangsodsai \\ Chulalongkorn University, Bangkok, Thailand \\ jaitipnegmail.com
}

\begin{abstract}
This study was conducted to develop a smartphone application to enhance self-efficacy for online learning. The theory of planned behaviour (TPB) was used as a framework for developing the smartphone app. The study used research and design (R\&D) through three phases: 1) examining relevant literature and interviewing recognized experts in the field, 2) developing the smartphone app, and 3) studying the effect of the smartphone app on the selfefficacy of online learners. The results demonstrated that the framework of the smartphone application based on the TPB comprised six components. They were 1) the TPB's concept for online learning, 2) instructional process, 3) instructional support tools, 4) application features, 5) instructor's role, and 6) learner's role. For technical aspects, the smartphone app was developed and deployed by using Amazon Web Service (AWS) cloud computing platform and infrastructure. Studying the effect of the application on self-efficacy was performed for four weeks using two groups in a pre-test/post-test design. The research method involved purposive sampling of 180 undergraduate students, consisting of a 90 -student experimental group and a 90 -student control group. The application based on the TPB and the application without the TPB were implemented in the experimental group and the control group, respectively. The results demonstrated that the post-test score of self-efficacy in online learning for the experimental group was statistically significantly higher than the control group at 0.05 level. This result showed that the smartphone app based on the TPB could significantly affect self-efficacy for online learners; it has the potential to be an effective tool for teaching an online course.
\end{abstract}

Keywords-Self-efficacy, online learning, theory of planned behaviour, smartphone application

\section{Introduction}

The evolution of mobile devices such as "smart" telephones and wireless technology have resulted in profound changes in people's lifestyles, including education, by allowing flexible and instant access to knowledge bases. Mobile learning ("mlearning") is a type of learning that happens when learners are not situated at a prede- 
termined location, or learning that happens when learners take advantage of learning opportunities offered by mobile technologies [1]. In other words, with the use of mobile devices, learners can learn anywhere and at any time [2]. Moreover, mobile device applications can be used as study aids that learners can access from virtually anywhere [3]. Consequently, education developers should consider the connotation of these mobile devices for the current teaching and learning environment.

One major problem encountered in online learning is dropout. Jordan [4] indicated that completion rate (percentage of learners who completed an online learning course) varied from $0.7 \%-52.1 \%$ with median value of $12.6 \%$. Dropout rate was also linked to a lack of self-efficacy [5]. Therefore, self-efficacy is critical to learning and performance [6]. Self-efficacy is the belief in one's capabilities to organize and execute the actions required to produce particular results [7]. If persons have a low level of selfefficacy toward a task, they are less likely to exert effort and accomplish the task.

The Theory of Planned Behaviour (TPB) defines that individual behaviour is forced by intentions, where intentions are a function of three considerations: 1) attitude toward behaviour; refers to the degree to which a person has a favorable or unfavorable evaluation or appraisal of the behaviour in question, 2) subjective norm; refers to the perceived social pressure to perform or not to perform the behavior, and 3 ) perceived behavioural control; refers to the perceived ease or difficulty of performing the behaviour [8]. In addition, perceived behavioural control is compatible with the concept of self-efficacy [9]. The TPB was commonly used as a framework for developing tools, i.e. mobile application and web-based intervention, to improve behaviour [10], [11], [12]. Few research on web-based learning and mobile applications for behavioural change has been studied. In the study of Hansen, et al. [12], determined an effect of web-based intervention on behavioural change was that it can be an effective tool in increasing the physical activity of users. In another web-based intervention, Davies, et al. [13] investigated that website intervention components helped to increase retention rates for engagement and physical activity changes in terms of steps per day. The results demonstrated that the relative effectiveness of interactive components enhanced website engagement. In addition, the results indicated that virtual walking buddies were associated with recording above-average step-log days. In the context of online learning, the TPB was also used as a framework for exploring factors affecting learners' adoption of online learning [14], [15], [16] and the relationships among those factors. According to the research of Khasawneh [14], studied the important factors regarding the usage of information communication and technology (ICT) in public universities among academic staff by applying the Decomposed Theory of Planned Behaviour (DTPB). The results showed that selfefficacy and facilitating condition had a significant effect on behavioural intention to use ICT. Moreover, there was a significant relationship between academic staff's perception of technological characteristics and perceived behavioural control. Cheon et al. [17] investigated the status of college students' perceptions toward mobile learning in higher education. A conceptual model based on the theory of planned behaviour was developed, which explains how college students' beliefs influence their intention to adopt mobile devices in their coursework. The results indicated that the TPB explained college students' acceptance of m-learning reasonably well. More 
specifically, attitude, subjective norm, and behavioural control positively influenced their intention to adopt mobile learning.

Literature reviews support that the compositions of the TPB are crucial factors toward the behavioural intention and behavioural change in any dynamic context including online learning. As a result, the purpose of this research is 1)to develop a smartphone application based on the theory of planned behaviour to support learning behaviour that leads to enhanced self-efficacy in the context of online learning, 2)to study the effect of using the developed application on self-efficacy in the context of online learning for undergraduate students. This paper was presented into six sections; 1 ) introduction 2) research objectives 3 ) research methodology which was divided into three phases: Firstly, examined a relevant literature and interviewed experts in the field. Secondly, created prototype and developed the smartphone application. Finally, studied the effect of using the developed smartphone application on learner selfefficacy 4) results of developing smartphone application and its effect on learner self-efficacy 5) discussion of the developed smartphone application and its effects on learner self-efficacy and 6) conclusion. .

\section{Objective}

To develop a smartphone application based on the theory of planned behaviour to enhance self-efficacy for online learning and study its effect on self-efficacy for online learning of undergraduate students.

\section{Methodology}

\subsection{Method}

The study was R\&D research to develop the smartphone application based on the theory of planned behaviour to enhance the self-efficacy for online learning. It was conducted in three phases:

Phase 1. To examine relevant literature and to interview recognized experts in the field. Literature review was conducted by synthesizing research on factors influencing self-efficacy in the contexts of online learning. The views of experts in educational psychology and in education technology were studied through in-depth interviews to gain an understanding about developing self-efficacy for online learning and to identify treatment variables in the TPB's elements.

Phase 2. To develop the smartphone application based on the TPB to enhance learner self-efficacy consisted of three sections: 1) developing a framework using the results from phase one, 2) creating a smartphone application, 3) testing usability with undergraduate students in computer science major, and 4) improving the smartphone application.

Phase 3. To study the effect of smartphones based on the TPB on self-efficacy for online learning. The experiment was performed using two groups with a pre-test/post- 
test design. The sample consisted of 180 undergraduate students from Southeast Asia University, Thailand and consisted of an experimental group and a control group with 90 students in each group. The experimental group was classified as 15 small learning groups (6 students per group), with each group comprised of members with multi-level (low, medium and high)self-efficacy. The experimental group and the control group were required to learn using the application based on the TPB and the application designed without the TPB for four weeks. Data of self-efficacy for online learning were analysed using independent sample t-test and paired sample t-test.

\subsection{Measurement}

The self-efficacy scale for online learning was developed as an instrument to measure learners' confidence in their own ability to successfully learn and perform activities in an online course. Following a literature review, the self-efficacy for online learning could be conceptualized into four aspects: self-regulated learning in an online course, learning achievement in an online course, learner-to-learner and learner-to-instructor interaction in an online course, and the use of an online course system [18], [19], [20], [21]. Self-efficacy for online learning was measured by quantitative methods. An 18-item questionnaire was used to collect the data. The instrument used a seven-point Likert scale $(1=$ cannot do, $4=$ can do with moderate confidence, and $7=$ can do with high confidence) to evaluate the degree of the learners' confidence for online learning. Each item passed evaluation through review by experts in educational psychology and in education technology. The reliability of the questionnaire was evaluated, and the Cronbach's alpha was 0.905 .

\section{Results}

\subsection{Results of the literature review and the study of experts' opinions through in-depth interviews}

The results of literature review with regard to factors influencing self-efficacy in the context of online learning are shown as Table 1. The literature review was conducted using the online research databases: ERIC, Scopus, and Web of Science. The results found that factors of self-efficacy consisted of 1) learning goal setting, 2) elaborate feedback, 3) offering reward, 4) content and system qualities, 5) student-tostudent and student-to-teacher interaction in online course, 6) peer support, 7) social influence 8) social presence in online environment, and 9) attitude and motivation toward online learning.

Results of the study of experts' opinions through in-depth interviews are shown as Table 2. It was essential information for developing the framework of the smartphone application based on theory of planned behaviour (TPB) to enhance online learner self-efficacy. 
Paper-Development of Smartphone Application Based on the Theory of Planned Behaviour to Enhance..

Table 1. Factors of self-efficacy in the context of online learning from literature review

\begin{tabular}{|l|l|}
\hline \multicolumn{1}{|c|}{ Authors } & \multicolumn{1}{c|}{ Factors of self-efficacy in the context of online learning } \\
\hline Law et al. [22] & Learning goal setting \\
\hline Wang and Wu [23] & Elaborate feedback \\
\hline Liou et al. [24] & Offering a reward \\
\hline Lim et al. [25] & Content and system qualities \\
\hline Lim et al. [25] & Student-to-student and student-to-teacher interaction in online course \\
\hline Chu and Chu [26] & Peer support \\
\hline Chiu and Tsai [27] & Social Influence \\
\hline Lin et al. [28] & Social presence in online environment \\
\hline $\begin{array}{l}\text { Prior et al. [29]; Hong et al. } \\
\text { [30]; Law et al. [22] }\end{array}$ & Attitude and motivation toward online learning \\
\hline
\end{tabular}

Table 2. Factors of self-efficacy in the context of online learning from experts' in-depth interview

\begin{tabular}{|l|l|}
\hline \multicolumn{1}{|c|}{ TPB's elements } & \multicolumn{1}{c|}{ Factors } \\
\hline Attitude toward Behaviour & $\begin{array}{l}\text { Course introduction, providing information about online course and how } \\
\text { to use the online course system. }\end{array}$ \\
\cline { 2 - 3 } & Design a user-friendly interface \\
\hline Subjective Norm & Establishing a small learning group with multi-levels of self-efficacy \\
\cline { 2 - 3 } & Assigning group work to support cooperative learning \\
\cline { 2 - 3 } & Showing peer models of those who performed a task successfully \\
\cline { 2 - 3 } & $\begin{array}{l}\text { Social media integration to enable students to share knowledge and } \\
\text { communicate in the online learning environment }\end{array}$ \\
\hline Perceived Behaviour Control & Personal goal setting for learners \\
\cline { 2 - 3 } & Progress and motivational feedback \\
\cline { 2 - 3 } & Offering a reward \\
\cline { 2 - 3 } & Self-monitoring for learners \\
\hline
\end{tabular}

\subsection{Framework for smartphone application based on the TPB to enhance self- efficacy for online learning}

Framework for developing the smart-phone application based on the TPB to enhance self-efficacy for online learning is shown as Figure 1. The framework was established using the TPB's concept. The results of literature review regarding factors influencing learner self-efficacy in the context of online learning and views of experts in educational psychology and in education technology were used to identify treatment variables in the TPB's elements. The framework for smartphone application consisted of six components: 1) the TPB's concept, 2) instructional process, 3) instructional support tools, 4) application features, 5) instructor's role, and 6) learners' role. The details are as follows:

The TPB's concept for smartphone application to enhance self-efficacy for online learning. Theory of planned behaviour was applied to develop the smartphone application to enhance learner self-efficacy. The constructs of the TPB 
consisted of three elements which were attitude toward online learning, subjective norms, and perceived behavioural control.

The TPB construct of attitude toward online learning included two aspects: 1) course introduction and 2) systems' user guide. This construct established the learners' perceived ease of use and perceived usefulness which led to building the positive attitude toward online learning, learning intention, and self-efficacy. The TPB construct of subjective norm or social norm was addressed with four elements: 1) small learning groups and group work. Small learning groups consisted of learners with multi-levels (low, medium and high)of self-efficacy where learners were required to work together, 2) interaction and communication, enabling learner to interact and communicate with their peers and instructor in online course, 3) social presence through the use of icebreakers and discussion helped to build learners' sense of community in an online learning environment. Icebreaker activities allowed learners to introduce themselves to their instructor and peers. In addition, the discussion refers to activities that allowed learners to share their knowledge and opinions, and 4) peer models were incorporated to permit learners to observe peers who performed tasks well. The last element of TPB was perceived behavioural control. This element was addressed with three aspects to enable learners to recognize their abilities. It consisted of: 1) personal goal setting, where learners were enabled to set goals for online learning and receive feedback on their progress. Moreover, they could track the progress immediately when performing tasks in the app., 2) selfmonitoring, where learners were enabled to observe and evaluate their behaviour, and 3 ) reward, which refers to offering a reward when they accomplished a task.

Instructional process. Instructional process for online learning in the smartphone application to enhance learner self-efficacy consisted of eight steps supplemented with three feedbacks.

1. Course introduction: provided information of how to learn in the course and how to use the app.

2. Group learning and group goal setting: established learning groups with multilevels (low, medium and high) of self-efficacy. Each group was assigned a goal that each member was required to perform together to attain a group score.

3. Personal goal setting: each learner had to select a specific number of days to complete the online learning course. The established goal helped to reinforce enactive mastery experiences which could lead to the development of self-efficacy.

4. Icebreakers: activities done to establish social presence. These activities involved members making a personal introduction by selecting eight nouns that accurately represented themselves. Learners were required to post a personal introduction and to post eight nouns that best described themselves on the discussion board.

5. Learning: learners were required to learn course contents via video consisting of online course materials.

6. Discussion: learners were required to share opinions and knowledge on the discussion board.

7. Self-monitoring: learners were required to observe and evaluate their own progress. 
8. Evaluation and reward: learners were evaluated by the differences between their pre-test and post-test results. Furthermore, learners were offered rewards when they could achieve their goals or sub-goals in each learning unit.

During the instructional process, learners were motivated by three feedbacks: 1) progress feedback, which provides information from the system about the percent of tasks which learners could complete in the online course, 2) peers' progress data feedback - system information on peers who performed a task well, and 3) persuasive feedback from instructor through direct online messaging.

Role of instructor and learners. Learners' role for online learning in the smartphone application, focused on the learning of and participation in all activities of the online learning course. Moreover, they were required to track their progress and to monitor their learning behaviour. The instructor's role in the online learning environment focused on learner assessment. The instructor would track learning behaviour and help learners use the system as well as provide persuasive feedback.

Instructional support tools. Tools for instructional support of the smartphone application based on the TPB consisted of: 1) a social media app, which was comprised of a discussion board and a Line chat room (a social media messenger application) to reinforce knowledge exchange and communication, 2) an online test and evaluation system, which was used to test and evaluate learners, 3) a behavioural tracking system, which was used to track learning behaviour in real-time and report the progress, 4) and streaming videos of course content, which allowed the transfer of contents via the internet without downloading files.

Application Features. Features were designed to support instructional processes and learners and were comprised of six aspects: establishing small learning groups, enabling learners to set individual goals, providing rewards, interfacing with social apps, providing real-time progress reports of individuals and groups, and sequential learning formats.

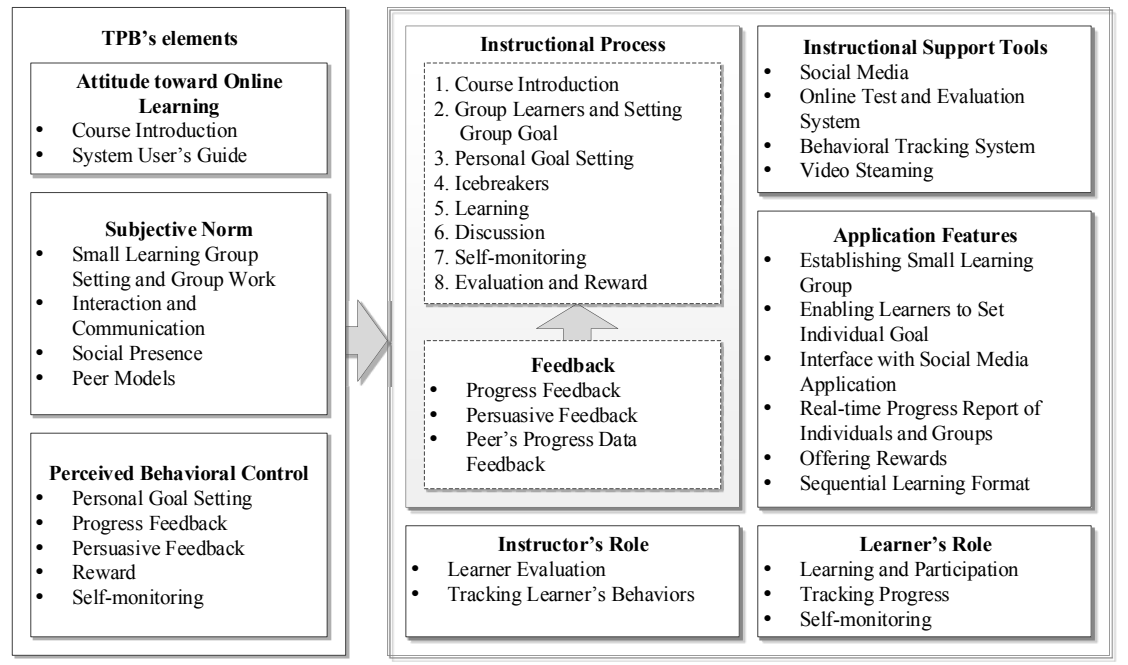

Fig. 1. Framework of smart-phone application based on the TPB to enhance self-efficacy for online learning 


\subsection{Development of smartphone application based on the TPB to enhance self- efficacy for online learning}

Development and system architecture. The application was developed for users by Xeersoft, a Thailand-based software developer. Agile methodology was used to help develop the software faster and to be more responsive to users' requirements. The application was deployed by using Amazon Web Service (AWS) platform for reliability and scalability of application. AWS reduced many deployment concerns such as low investment in infrastructure cost, flexible server capacity, reliability of database storage, and stability of content delivery across a variety of devices. Moreover, the AWS platform has many modules and components that can help add sophisticated application features such as behaviour tracking and analytics, and machine learning or augmented reality in the future. Amazon Relational Database Service (Amazon RDS) was also used as a distributed relational database service to help reduce administration processes such as patching the database software, backing up databases and enabling point-in-time recovery, which the system managed automatically. To ensure application uptime and users' resolution management, Fabricio's crashlytics was used to help monitor the behaviour of users' usage and to detect application problems. This real-time feedback was vital to determine how users engaged with applications, what actions they took most, and how their behaviour changed over time. Gitlab tool was used to manage issues and to identify, track, and resolve users' problems. Managing and running a native application for large numbers of students who use a wide range of devices can be quite a challenge. Consistently using a problem tracking system and having competent IT support personal are crucial requirements for successfully deploying applications. The Software Architecture of Application is shown in Figure 2.

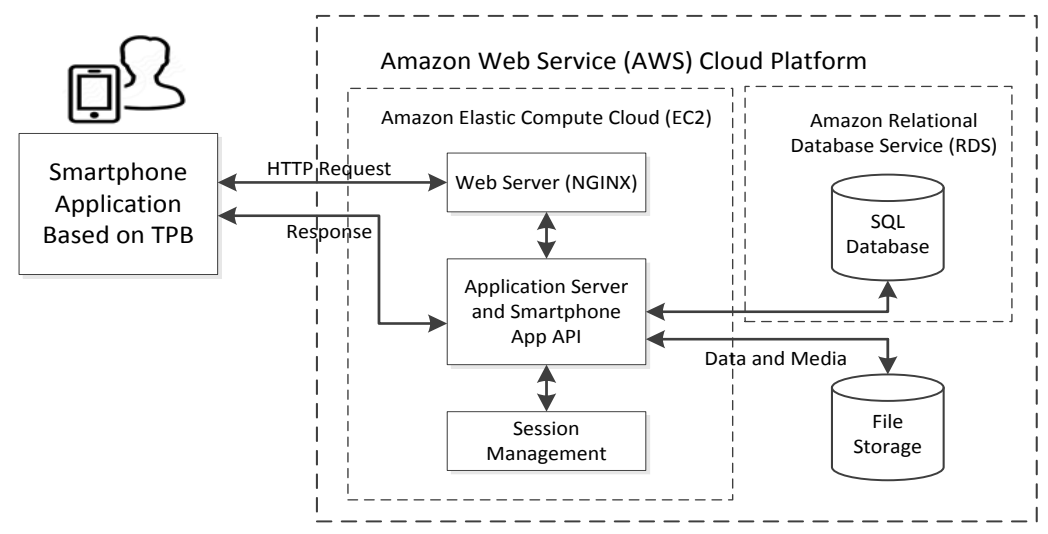

Fig. 2. Software Architecture

Feature aspects. The features were designed to support the learners' instructional processes for smartphone applications based on the TPB to enhance self-efficacy for online learning. It consisted of six aspects: establishing small learning groups, enabling learners to set individual goals, providing rewards, interfacing with social media applications, providing real-time progress reports of individuals and groups, and 
sequential learning format. Figure 3 shows the application screen: (A) goal setting that enables learners to set a target number of days and a time to complete the online learning course, (B) learner's course that displays video-based contents and activities, learning progress as compared with goal, and group members' bar. The contents and learning activities of the online course are arranged sequentially. The group members' bar can change color when they complete goals, (C) learner's group that displays progress and rewards of that group's individual members as well as that group's progress. Furthermore, learners can access Line Social Media Application's chat room via link as shown on the screen, (D) a leaderboard that displays the progress of the top-ten groups and their rewards, (E) group members' course and progress (F) individual's score and reward.

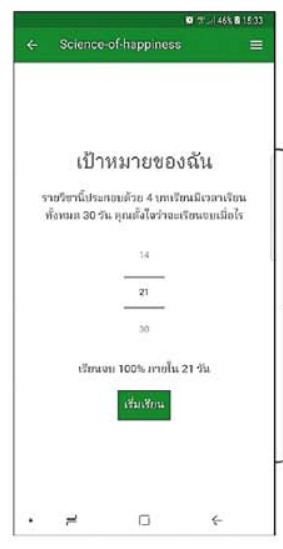

(A)

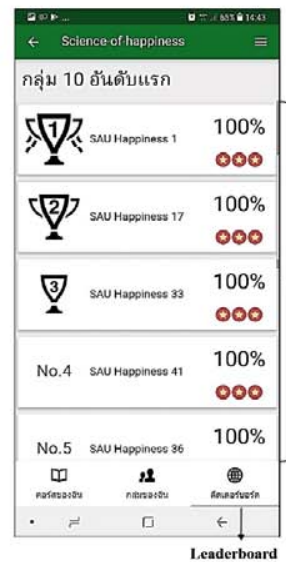

(D)

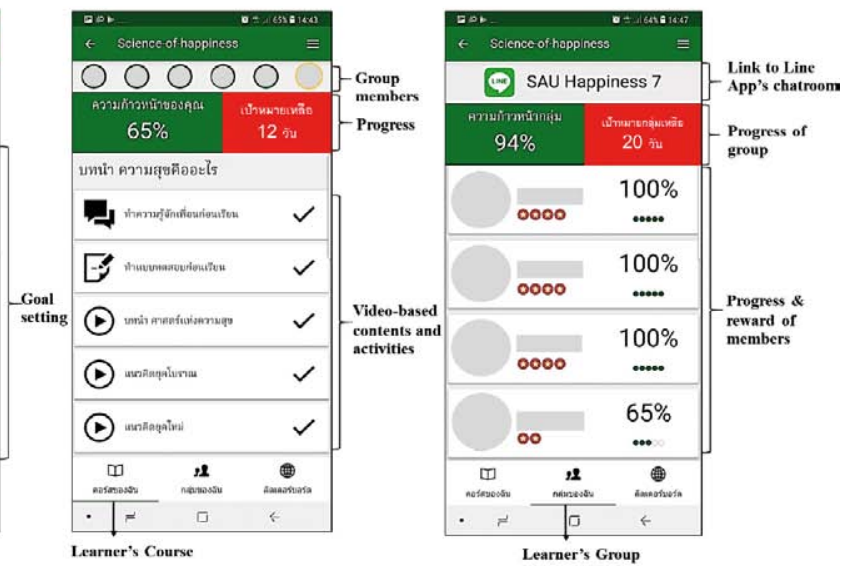

(B)

(C)

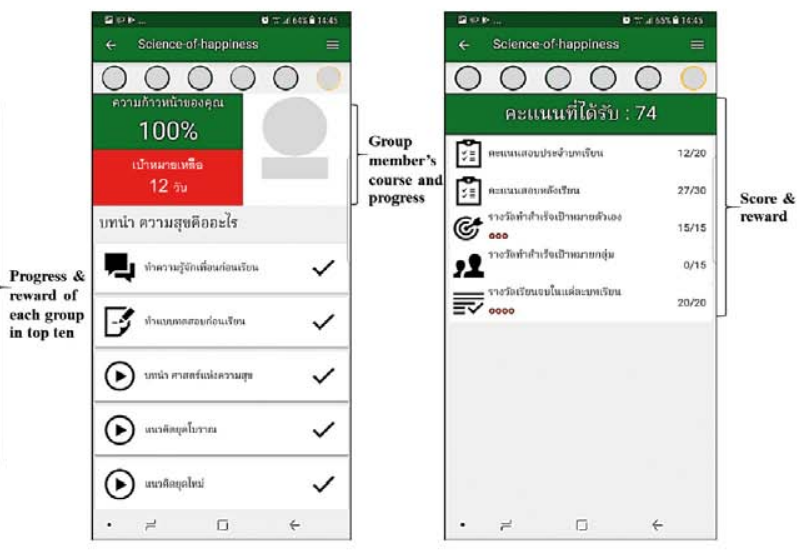

(E)

(F)

Fig. 3. Screen of smartphone application based on the TPB to enhance self-efficacy for online learning: (A) goal setting, (B) learner's course, (C) learner's group, (D) leaderboard,

(E) group members' course and progress, and (F) individual's score and reward. 


\subsection{Usability testing of smartphone application based on the TPB}

Usability testing for smart-phone application based on the TPB to enhance self- efficacy was evaluated by quantitative method with three measurements: effectiveness, efficiency, and satisfaction. The results demonstrated that the subjects had a positive opinion of the smartphone application for online learning. All aspects of measurement were at a good level which consisted of effectiveness $4.08 \pm 0.65$, efficiency $3.83 \pm 0.87$, and satisfaction $3.72 \pm 0.57$ (Table 3 ). From the inquiry, some users found some errors in the test system and some software problems on the discussion board. The problems were fixed before the software was deployed with the sample group.

Table 3. Usability testing of smartphone application based on the TPB

\begin{tabular}{|c|c|c|c|c|}
\hline $\begin{array}{c}\text { Metric of } \\
\text { evaluation }\end{array}$ & Definition & Point of Survey & X-bar & S.D \\
\hline \multirow{5}{*}{ Effectiveness } & \multirow{5}{*}{$\begin{array}{l}\text { Users' ability for } \\
\text { completing } \\
\text { a task }\end{array}$} & $\begin{array}{l}\text { Users are able to log in to the } \\
\text { application and find course } \\
\text { information }\end{array}$ & 4.50 & 0.50 \\
\hline & & $\begin{array}{l}\text { Users are able to understand the } \\
\text { contents and activities presented } \\
\text { in the online course }\end{array}$ & 3.83 & 0.37 \\
\hline & & $\begin{array}{l}\text { Users are able to find the pro- } \\
\text { gress feedback }\end{array}$ & 4.33 & 0.75 \\
\hline & & $\begin{array}{l}\text { Users are able to access learning } \\
\text { group and communication tools }\end{array}$ & 3.67 & 0.47 \\
\hline & & Total & 4.08 & 0.65 \\
\hline \multirow{6}{*}{ Efficiency } & \multirow{6}{*}{$\begin{array}{l}\text { System's response to } \\
\text { users for completing } \\
\text { tasks }\end{array}$} & $\begin{array}{l}\text { Response from system for login } \\
\text { into the application }\end{array}$ & 3.50 & 0.96 \\
\hline & & $\begin{array}{l}\text { Response from system for } \\
\text { accessing application's menu }\end{array}$ & 3.33 & 0.94 \\
\hline & & $\begin{array}{l}\text { Response from system for using } \\
\text { communication tools }\end{array}$ & 3.67 & 0.47 \\
\hline & & $\begin{array}{l}\text { Response from system for } \\
\text { viewing video and using online } \\
\text { test }\end{array}$ & 4.17 & 0.69 \\
\hline & & $\begin{array}{l}\text { Response from system for } \\
\text { providing progress feedback }\end{array}$ & 4.50 & 0.50 \\
\hline & & Total & 3.83 & 0.87 \\
\hline \multirow{4}{*}{ Satisfaction } & \multirow{4}{*}{$\begin{array}{l}\text { User's satisfaction for } \\
\text { application use }\end{array}$} & $\begin{array}{l}\text { Users' satisfaction for interface } \\
\text { design }\end{array}$ & 3.67 & 0.47 \\
\hline & & Users' satisfaction for efficiency & 3.50 & 0.50 \\
\hline & & $\begin{array}{l}\text { Users' satisfaction for application } \\
\text { use }\end{array}$ & 4.00 & 0.58 \\
\hline & & Total & 3.72 & 0.57 \\
\hline
\end{tabular}




\subsection{Effect of smartphone application based on the TPB to enhance self- efficacy for online learning}

The study of the effects of smartphone application based on the TPB to enhance selfefficacy for online learning was conducted with 180 undergraduate students using two groups with a pretest-posttest design method. Ninety undergraduate students in the experimental group were required to use the smartphone app based on the TPB. In the control group, the 90 undergraduate students were required to use the smartphone app for online learning designed without the TPB. Each group learned via the smartphone app which contained the same content (positive psychology subject) and learned in the same period. Therefore, both groups use the same course contents and the contents will not be a variable factors in this experiment. Self-efficacy for online learning was measured with four aspects: self-regulated learning in online course, learning achievement in online course, learner-to-learner and learner-to-instructor interaction in online course, and the use of an online course system. The results are shown in Tables 4 to 6 . The percent of completion (percent of students who completed online course) and average progress (percent of tasks which were completed) of the experimental group were 82.22 and $90.17 \%$, respectively. It was significantly higher than the control group. In the experimental group, the average post-test score of self-efficacy for online learning was statistically significantly higher than the pre-test score at 0.05 level. In addition, the average post-test score of self-efficacy for online learning of the experimental group was higher than the control group at 0.05 level. The results demonstrated that the smartphone application based on the theory of planned behaviour affected the self-efficacy for online learning of undergraduate students.

Table 4. Comparison of completion rates and learning progress for online learning of experimental group and control group

\begin{tabular}{|l|c|c|c|c|c|}
\hline \multirow{2}{*}{\multicolumn{1}{c|}{ Sample Groups }} & \multirow{2}{*}{$\begin{array}{c}\text { Completion } \\
\text { Rates (\%) }\end{array}$} & \multicolumn{3}{c|}{ Learning Progress (\%) } \\
\cline { 3 - 5 } & & Mean & S.D & $\boldsymbol{t}$ & Sig. \\
\hline Experimental Group & 82.22 & 90.17 & 23.611 & \multirow{2}{*}{8.761} & $0.000 *$ \\
\hline Control Group & 24.44 & 47.31 & 39.955 & & \\
\hline
\end{tabular}

$* \mathrm{P}<0.05$

Table 5. Comparison of pre-test and post-test score of self-efficacy in online learning for experimental group

\begin{tabular}{|c|c|c|c|c|c|}
\hline Measure & Phase & Mean & S.D & $\mathbf{t}$ & Sig. \\
\hline \multirow{2}{*}{$\begin{array}{l}\text { 1. Self-efficacy for self-regulated } \\
\text { learning in online course }\end{array}$} & Pre-test & 4.431 & 0.823 & \multirow{2}{*}{-10.005} & \multirow{2}{*}{$0.000 *$} \\
\hline & Post-test & 5.711 & 1.020 & & \\
\hline \multirow{2}{*}{$\begin{array}{l}\text { 2. Self-efficacy for learning } \\
\text { achievement in online course }\end{array}$} & Pre-test & 4.355 & 0.892 & \multirow{2}{*}{-8.952} & \multirow{2}{*}{$0.000 *$} \\
\hline & Post-test & 5.559 & 0.950 & & \\
\hline \multirow{2}{*}{$\begin{array}{l}\text { 3. Self-efficacy for interaction in } \\
\text { online learning }\end{array}$} & Pre-test & 4.557 & 1.015 & \multirow{2}{*}{-4.556} & \multirow{2}{*}{$0.000 *$} \\
\hline & Post-test & 5.185 & 1.000 & & \\
\hline \multirow{2}{*}{$\begin{array}{l}\text { 4. Self-efficacy for the use of online } \\
\text { course system }\end{array}$} & Pre-test & 4.544 & 0.976 & \multirow{2}{*}{-8.026} & \multirow{2}{*}{$0.000 *$} \\
\hline & Post-test & 5.622 & 0.986 & & \\
\hline \multirow{2}{*}{ Average } & Pre-test & 4.472 & 0.807 & \multirow{2}{*}{-9.236} & \multirow{2}{*}{$0.000^{*}$} \\
\hline & Post-test & 5.519 & 0.850 & & \\
\hline
\end{tabular}

$* \mathrm{P}<0.05$ 
Paper-Development of Smartphone Application Based on the Theory of Planned Behaviour to Enhance...

Table 6. Comparison of post-test score for self-efficacy in online learning of experimental group and control group

\begin{tabular}{|l|c|c|c|c|c|c|}
\hline \multirow{2}{*}{ Measure } & \multicolumn{2}{|c|}{ Experimental Group } & \multicolumn{2}{c|}{ Control Group } & \multirow{2}{*}{ t } & \multirow{2}{*}{ Sig. } \\
\cline { 2 - 6 } & Mean & S.D & Mean & S.D & & \multirow{2}{*}{$0.000^{*}$} \\
\hline $\begin{array}{l}\text { 1. Self-efficacy for self- } \\
\text { regulated learning in online } \\
\text { course }\end{array}$ & 5.711 & 1.020 & 4.691 & 1.070 & 6.543 & 0.933 \\
\hline $\begin{array}{l}\text { 2. Self-efficacy for learning } \\
\text { achievement in online course }\end{array}$ & 5.559 & 0.950 & 4.622 & 6.672 & $0.000^{*}$ \\
\hline $\begin{array}{l}\text { 3. Self-efficacy for interac- } \\
\text { tion in online course }\end{array}$ & 5.185 & 1.000 & 4.624 & 0.980 & 3.799 & $0.000^{*}$ \\
\hline $\begin{array}{l}\text { 4. Self-efficacy for the use of } \\
\text { online course system }\end{array}$ & 5.622 & 0.986 & 4.783 & 1.047 & 5.530 & $0.000^{*}$ \\
\hline Average & 5.519 & 0.850 & 4.680 & 0.887 & 6.478 & $0.000^{*}$ \\
\hline
\end{tabular}

$* \mathrm{P}<0.05$

\section{Discussion}

The findings of this study demonstrated that the framework of the smartphone application to enhance self-efficacy for online learning developed by the concept of the theory of planned behaviour consisted of six core elements: 1) the TPB's concept with three components that were attitude toward online learning, subjective norm, and perceived behavioural control, 2) instructional process, 3) instructional support tools, 4) instructor's role, 5) learners' role, and 6) application features. The instructional process was developed by the TPB's concept that consisted of eight steps supplemented with three feedbacks. The eight steps for instructional process were: 1) course introduction, 2) grouping learners and group goal setting, 3) personal goal setting, 4) icebreakers, 5) learning, 6) discussion, 7) self-monitoring, and 8) evaluation and reward. The three feedbacks for instructional process were 1) progress feedback, 2) persuasive feedback, and 3) peers' progress data feedback.

Results of studying the effect of the smartphone application on self-efficacy for online learning demonstrated that in the experimental group the average post-test score was statistically significantly higher than the pre-test scores, and was higher than the average post-test score of the control group at the 0.05 level. Moreover, the feedback of students who participated in online learning via smartphone application based on the TPB showed a positive online learning experience, and it was classified into the following five groups:

Knowledge sharing and communication. Students commented that they were able to share knowledge and communicate with their friends in the online learning environment. For example:

"An advantage was being able to share knowledge and communicate with group members"

"I liked this application because it was easy to use, and I was able to exchange knowledge" 
Useful and easy to learning. Some students perceived the usefulness and ease of learning. For example:

"I feel that contents were easy to learn, and I got more knowledge also"

"Course contents were not too difficult to learn"

Easy and effective use. Students perceived the ease of using the application as follows;

"It worked well; I could learn how to use it quickly"

"It was smooth to use and easy to use"

"It worked well"

"I like this program; it worked quite well"

Personal goal setting. Students' opinions were positive about learning goal setting as follows:

"The application enabled me to select a number of days for completing the online course"

"I liked that I was able to set a time for completing the online course and to check my progress all the time"

Receiving immediate progress feedback. Students' opinions were positive about receiving progress feedback as follows:

"I liked this application; it enabled me to perceive my progress and to check it all the time"

"It was excellent that I was able to get progress feedback"

"It was easy to learn. I was able to perceive my progress"

The process of grouping learners was established to create group norms with each group comprised of members with multi-levels of self-efficacy. This step enabled learners to work together. Individual members were able to observe peers who performed tasks successfully as role models and that led them to develop greater self-efficacy. These results are consistent with Ontas \& Tekindal [31], who found that group work positively affected the self-efficacy of learners. Further, results agreed with Bandura [7], who indicated that modeling was an effective tool for supporting one's sense of selfefficacy. The course introduction step provided information about the learning course and how to use the online learning system. The objective of this step was to reinforce the attitudes of learners that facilitated them to develop self-efficacy. This is consistent with Law, et al. [22], who reported that individual attitude and expectation had a significant and positive relationship with self-efficacy. Additionally, research of Prior, et al. [29] showed that attitude significantly affected self-efficacy in online learning. The steps of personal goal setting, learning and evalu-ation enabled learners to set goals themselves and then learn content as well as per-form activities to achieve their goals. It was addressed as perceived behavioural con-trol construct that could lead to promoting self-efficacy. Self-efficacy was formed when learners obtained progress feedback and achieved their goal [32]. According to Bandura [7], the progress of goal achievement can lead to an enactive mastery experience that can result in developing self-efficacy. The steps of icebreakers and discussion were activities that helped to establish the social presence in the online learning environment. Social presence was addressed in subjective norm or social norm that could lead to encouraging a sense of community and learners' self-efficacy. Scheg and Shaw [33] indicated that icebreakers helped in building social presence in online learning environments. Moreover, Akcaoglu and Lee [34] indicated that small group discussion can promote a social presence in online learning 
environments. Self-monitoring was conducted to promote self-efficacy. Schunk [35] indicated that self-monitoring significantly affects self-efficacy and learner achievement. In the evaluation and reward step, learning is evaluated and students are given a reward to reinforce their motivation and sense of efficacy. In the instructional process for online learning, learners are motivated by progress feedback, providing data of their peers' progress from the system, and persuasive feedback from the instructor to promote their positive behaviour and sense of self-efficacy. The results show that the smartphone application can be effective learning tools for enhancing learning behaviour and selfefficacy of online learner.

\section{Conclusion}

This research presented development of a smartphone application to enhance selfefficacy for online learning. The theory of planned behaviour consisted of three components (attitude toward online learning, subjective norm, and perceived behavioural control)and was used as a concept to create a framework for the smartphone application's development to enhance self-efficacy for online learning. The instructional process was developed by the TPB's concept and consisted of eight steps supplemented with three feedbacks. The eight steps for instructional process were 1) course introduction, 2) grouping learners and group goal setting, 3) personal goal setting, 4) icebreakers, 5) learning, 6) discussion, 7) self-monitoring, and 8) evaluation and reward. The three feedbacks of the instructional process were 1) progress feedback 2) persuasive feedback and 3) peers' progress data feedback. The technical aspects for developing the smartphone application were deployed by using Amazon Web Service (AWS)cloud computing platform and infrastructure. The smartphone application based on the TPB cloud significantly affected self-efficacy for online learning. Consequently, the smartphone application has the potential to be an effective tool for teaching in an online course to enhance the self-efficacy of learners to promote learning achievement.

\section{$7 \quad$ References}

[1] Malley, C.O., et al. (2005). Guidelines for learning/teaching/tutoring in a mobile environment. MOBILearn project (D.4.1) 2005. Retrieved from https://hal.archivesouvertes.fr/hal-00696244.

[2] Crescente, M.L., \& Lee, D. (2011). Critical issues of M-Learning: design models, adoption processes, and future trends. Journal of the Chinese Institute of Industrial Engineers, 28(2): 111-123. https://doi.org/10.1080/10170669.2010.548856

[3] Young, J.R. (2011). Smartphones on campus: the search for 'killer' apps. The Chronicle of Higher Education. Retrieved from https://www.chronicle.com/article/Smartphones-onCampus-the/127397.

[4] Jordan, K. (2015). Massive Open Online Course Completion Rates Revisited: Assessment, Length and Attrition. International Review of Research in Open and Distributed Learning, 16(3): 341-358. https://doi.org/10.19173/irrodl.v16i3.2112 
Paper-Development of Smartphone Application Based on the Theory of Planned Behaviour to Enhance...

[5] Lee, Y., \& Choi, J. (2011). A review of online course dropout research: Implications for practice and future research. Educational Technology Research and Development, 59: 593-618. https://doi.org/10.1007/s11423-010-9177-y

[6] Hodges, C.B. (2008). Self-efficacy in the context of online learning environments: A review of the literature and directions for research. Performance Improvement Quarterly, 20(3-4): 7-25. https://doi.org/10.1002/piq.20001

[7] Bandura, A. (1997). Self-efficacy: The exercise of control. New York: W.H. Freeman.

[8] Ajzen, I. (1991). The Theory of Planned Behaviour. Organizational Behaviour and Human Decision Processes, 50: 179-121. https://doi.org/10.1016/0749-5978(91)90020-T

[9] Ajzen, I., (2002). Perceived Behavioral Control, Self-Efficacy, Locus of Control, and the Theory of Planned Behavior. Journal of Applied Social Psychology, 32(4): 665-683. https://doi.org/10.1111/j.1559-1816.2002.tb00236.x

[10] Honglu, D.G., Michael, Y., \& Peter, P. (2014). Efficacy of a Smartphone System to Support Groups in Behaviour Change Programs. $14^{\text {th }}$ International Conference on Wireless Health. Bethesda, October 29-31 2014, Maryland, USA. pp 1-8.

[11] Stroulia, E. (2013). Smart-phone Application Design for Lasting Behavioural Changes. $26^{\text {th }}$ IEEE International Symposium on Computer-Based Medical Systems, University of Porto, June 20-22 2013, Porto, Portugal. pp 291-296. https://doi.org/10.1109/ CBMS.2013.6627804

[12] Hansen, A.W., Grønbæk, M., Helge, J. W., Severin, M., Curtis, T., \& Tolstrup, J. S. (2012). Effects of a web-based intervention to promote physical activity and improve health among physically inactive adults: A population based randomized control trial. Journal of Medical Internet Research. 14(5): e145, https://doi.org/10.2196/jmir.2109

[13] Davies, C., Corry, K., Van Itallie, A., Vandelanotte, C., Caperchione, C., \& Mummery, W. K. (2012). Prospective associations between intervention components and website engagement in a publicly available physical activity website: The case of 10,000 steps Australia. Journal of Medical Internet Research, 14(1): e4, https://doi.org/10.2196/jmir.1792

[14] Khasawneh, M. (2015). Factors Influence e-Learning Utilization in Jordanian Universities- Academic Staff Perspectives. Procedia - Social and Behavioural Sciences, 210: 170-180. https://doi.org/10.1016/j.sbspro.2015.11.356

[15] Santos, R.D., Miguel, L., \& Shintaro, O. (2016). Planned e-Learning Adoption and Occupational Socialisation in Brazilian Higher Education. Studies in Higher Education, 41(11): 1974-1994. https://doi.org/10.1080/03075079.2015.1007940

[16] Ndubisi, N. (2006). Factors of Online Learning Adoption: A Comparative Juxtaposition of the Theory of Planned Behaviour and the Technology Acceptance Model. International Journal on E-Learning, 5(4): 571-591.

[17] Cheon, J., Lee, S., Crooks, S.M., \& Song, J. (2012). An investigation of mobile learning readiness in higher education based on the theory of planned behaviour. Computers \& Education, 59: 1054-1064. https://doi.org/10.1016/j.compedu.2012.04.015

[18] Bandura, A. (1996). Multifaceted Impact of Self-efficacy beliefs on academic functioning. Child Development, 67(3): 1206-1222. https://doi.org/10.2307/1131888

[19] Shen, D., Cho, M.H., Tsai, C.L., \& Marra, R. (2013). Unpacking online learning experiences: Online learning self-efficacy and learning satisfaction. Internet and Higher Education, 19: 10-17. https://doi.org/10.1016/j.iheduc.2013.04.001

[20] Pituch, K.A., \& Lee, Y.K. (2006). The influence of system characteristics on e-learning use. Computers \& Education, 47: 222-244. https://doi.org/10.1016/j.compedu.2004.10.007

[21] Artino, A.R., \& McCoACH, D.B. (2008). Development and initial validation of the online learning value and self-efficacy scale. Educational Computing Research, 38(3): 279-303. https://doi.org/10.2190/EC.38.3.c 
Paper-Development of Smartphone Application Based on the Theory of Planned Behaviour to Enhance...

[22] Law, K.M.Y., Lee, V.C.S., \& Yu, Y.T. (2010). Learning motivation in e-learning facilitated computer programming courses. Computers \& Education, 55: 218-228. https://doi.org/10.1016/j.compedu.2010.01.007

[23] Wang, S.L., \& Wu, P.Y. (2008). The role of feedback and self-efficacy on web-based learning: The social cognitive perspective. Computers \& Education, 51: 1589-1598. https://doi.org/10.1016/j.compedu.2008.03.004

[24] Liou, D.K., Chih, W.H., Yuan, C. Y., \& Lin, C. Y. (2016). The study of the Antecedents of Knowledge sharing behavior: The empirical study of Yamol online test community. Internet Research, 26(4): 845-868. https://doi.org/10.1108/IntR-10-2014-0256

[25] Lim, K., Kang, M., \& Park, S.Y. (2016). Structural relationships of environments, Individuals, and learning outcomes in Korean online university settings. International Review of Research in Open and Distributed Learning, 17(4): 315-330. https://doi.org/10.19173/ irrodl.v17i4.2500

[26] Chu, R.J., \& Chu, A.Z. (2010). Multi-level analysis of peer support, Internet self-efficacy and e-learning outcomes-The contextual effects of collectivism and group potency. Computers \& Education, 55: 145-154. https://doi.org/10.1016/j.compedu.2009.12.011

[27] Chiu, Y.L. \& Tsai, C.C. (2014). The roles of social factor and internet self-efficacy in nurses' web-based continuing learning. Nurse Education Today, 34: 446-450. https://doi.org/10.1016/j.nedt.2013.04.013

[28] Lin, S., Hung, T.C., \& Lee, C.T. (2015). Revalidate forms of presence in training effectiveness: Mediating effect of Self-Efficacy. Journal of Educational Computing Research, 53(1): 32-54. https://doi.org/10.1177/0735633115588772

[29] Prior, D.D., Mazanov, J., Meacheam, D., Heaslip, H., \& Hanson, J. (2016). Attitude, digital literacy and self-efficacy: Flow-on effects for online learning behavior. The Internet and Higher Education, 29: 91-97. https://doi.org/10.1016/j.iheduc.2016.01.001

[30] Hong, J.C., Hwang, M.Y., Tai, K.H., \& Lin, P.H. (2017). Intrinsic motivation of Chinese learning in predicting online learning self-efficacy and flow experience relevant to students' learning progress. Computer assisted language learning, 30(6): 552-574. https://doi.org/10.1080/09588221.2017.1329215

[31] Ontsas, O.C., \& Tekindal, T.M. (2015). The effect of group work on the self-efficacy of social work students. Precedia-Social and Behaviour Science, 174: 1124-1128. https://doi.org/10.1016/j.sbspro.2015.01.804

[32] Kultawanich, K., Koraneekij, P., \& Na-Songkhla, J. (2015). A Proposed Model of Connectivism Learning Using Cloud-based Virtual Classroom to Enhance Information Literacy and Information Literacy Self-efficacy for Undergraduate Students. Social and Behavioral Sciences, 191: 87-92. https://doi.org/10.1016/j.sbspro.2015.04.394

[33] Scheg, A.G., \& Shaw, M. (2017). Fostering effective student communication in online learning graduate course. Hershey, Pennsylvania: IGI Global.

[34] Akcaoglu, M., \& Lee, E. (2016). Increasing social presence in online learning through small group discussion. International Review of Research in Open and Distributed Learning, 17(3) 2-17. https://doi.org/10.19173/irrodl.v17i3.2293

[35] Schunk, D.H. (1983). Progress self-monitoring: Effects on children's self-efficacy and achievement. Journal of Experimental Education, 51: 89-93. https://doi.org/10.1080/00 $\underline{220973.1982 .11011845}$ 


\section{Authors}

Chattavut Peechapol is currently a Ph.D. student in the Technopreneurship and Innovation Management Program at the Chulalongkorn University, Bangkok 10330, Thailand. He also works at the Southeast Asia University, Bangkok, Thailand. His main research interests are in educational innovation and information technology management. E-mail: provut@gmail.com

Jaitip Na-Songkhla is currently an Associate Professor in the Department of Educational Technology and Communications, Chulalongkorn University, Bangkok 10330, Thailand. Her main research interests are educational technology development and educational policy studies. E-mail: jaitipn@gmail.com

Siridej Sujiva is currently an Associate Professor in the Department of Educational Research and Psychology, Faculty of Education, Chulalongkorn University, Bangkok 10330, Thailand. His main research interests are educational measurement and evaluation. E-mail: ssiridej@chula.ac.th

Arthorn Luangsodsai is currently a Lecturer in the Department of Mathematics and Computer Science, Faculty of Science, Chulalongkorn University, Bangkok 10330, Thailand. His main research interests are model-based slicing, program slicing, software engineering, outlier detection, information management, databases and cloud computing. E-mail: arthorn.1@chula.ac.th

Article submitted 09 April 2018. Resubmitted 26 June 2018. Final acceptance 23 July 2018. Final version published as submitted by the authors. 